\title{
TIMES-EU: A PAN-EUROPEAN MODEL INTEGRATING LCA AND EXTERNAL COSTS
}

\author{
S. KYPREOS ${ }^{1}$, M. BLESL ${ }^{2}$, C. COSMI ${ }^{3}$, A. KANUDIA ${ }^{4}$, R. LOULOU ${ }^{4}$, K. SMEKENS $^{5}$, M. SALVIA ${ }^{3}$, \\ D. VAN REGEMORTER ${ }^{6} \&$ V. CUOMO ${ }^{3}$ \\ ${ }^{1}$ PSI - Paul Scherrer Institut, Switzerland. \\ ${ }^{2}$ IER- Institute of Energy Economics and the Rational Use of Energy, University of Stuttgart, Germany. \\ ${ }^{3}$ IMAA - Institute of Methodologies for Environmental Analysis, CNR - National Research Council, Italy. \\ ${ }^{4}$ KANLO and McGill University, Canada. \\ ${ }^{5} \mathrm{ECN}$ - Energy Research Centre of the Netherlands, Unit Policy Studies, The Netherlands. \\ ${ }^{6}$ Center for Economic Studies, KUL - Catholic University of Leuven, Belgium.
}

\begin{abstract}
This paper deals with an experience of cooperative research carried out in the context of EU Sixth Framework Programme's Integrated Project New Energy Externalities Developments for Sustainability (NEEDS, 2004-2008), and in particular in the research stream 2a 'Modelling internalisation strategies including scenario building', co-ordinated by the IMAA, CNR. The main objective of this work is to analyse scenarios with generated partial equilibrium technology rich energy models of 29 countries (EU-25 States plus Iceland, Norway, Romania, Switzerland), integrated into a Pan-European model, capable of analysing the impacts of different policies and price mechanisms, and also evaluating them at technology level both at the country level and from an EU-wide perspective. All these models are characterised by a multi-period structure (base-year: 2000, last milestone year: 2050) and will include, in the Pan-European model, the most important life-cycle emissions, materials, and costs analysed by other NEEDS research streams (life cycle assessment and ExternE). This paper describes the current status of the work carried out in research stream 2a, including the basic methodological assumptions and scenario generation.
\end{abstract}

Keywords: demand drivers, external costs, ExternE, life cycle assessment, NEEDS, Pan-European model, reference energy system, TIMES-EU.

\section{INTRODUCTION}

NEEDS, 'New Energy Externalities Developments for Sustainability' [1], is a 4-year Integrated Project of the Sixth Framework Programme (Priority 6.1: Sustainable Energy Systems, Sub-priority 6.1.3.2.5: Socio-economic tools and concepts for energy strategy). Started officially on 1 September 2004, its ultimate objective is to evaluate the full costs and benefits (i.e. direct and external) of energy policies and of future energy systems, both at the level of individual countries and for the enlarged EU as a whole. In this context, NEEDS refines and develops the externalities methodology already set up in the ExternE project, through an ambitious attempt to develop, implement and test an original framework of analysis to assess the long term sustainability of energy technology options and policies.

NEEDS is structured as a series of research streams to entail major advancements in the current state of knowledge in four main areas:

- Life cycle assessment (LCA) of energy technologies.

- Monetary valuation of externalities associated with energy production, transport, conversion and use.

- Integration of LCA and external costs information into policy formulation and scenario building.

- Multi-criterion decision analysis, to examine the robustness of the proposed technological solutions with respect to stakeholder preferences.

(C) 2008 WIT Press, www.witpress.com

ISSN: 1743-7601 (paper format), ISSN: 1743-761X (online), http://journals.witpress.com

DOI: 10.2495/SDP-V3-N2-180-194 
The NEEDS consortium includes 66 partners (of which some 15\% are SMEs), representing 26 countries (12 Member States from the EU-15, 9 new EU Member States, 3 Mediterranean countries, and 2 countries from other parts of the world). It presents a balanced mix of universities, research institutions (both public and private), industry, and NGOs. Most leading institutions active in the area of energy externalities research are represented.

The work described in this paper deals with the activities of the research stream 2a 'Modelling internalisation strategies including scenario building', which is aimed at generating a partial equilibrium economic model of the EU energy system built upon the 29 country models linked by trades of energy and emissions as well as to provide a coherent and integrated scenario analysis platform. These models will extend the usual boundaries of energy system analysis to include in their long-term development, the most important emissions, materials, and externalities used by LCA and ExternE. The methodology and the major models' features are discussed in the following sections.

\section{METHODOLOGY}

The modelling platform for the development of the country models and the Pan-European model is The Integrated MARKAL-EFOM System (TIMES), developed by the Energy Technology Systems Analysis Programme (ETSAP) [2] of the International Energy Agency, and widely used to implement national and global models worldwide [3-6]. Several NEEDS partners are also members of ETSAP and expert developers and users of the TIMES methodology. The main components of this integrated platform are:

- A set of data files that fully describe the energy system (technologies, commodities, resources and demands for energy services) in a format compatible with the associated model generator.

- The model generator [7], consisting of the source code written in the General Algebraic Modeling System (GAMS) [8] computer programming language. It processes the data files, generates the matrix that specifies the mathematical programming problem, and post-processes the optimisation results.

- A solver, consisting of a software package integrated with GAMS, which solves the mathematical programming problem.

- A 'shell', i.e. a user interface named the versatile data analyst (VEDA) [9], that allows creating and managing the data input, running the model generator, and analysing results.

A consistent preliminary work performed a detailed characterisation of the scope and objectives of the analysis, which dealt with the following questions:

- What are the possible uses of the future model in the NEEDS as well as in other projects?

- What are the characteristics of the basic energy balances and other data sources to which the model will be calibrated?

Particular care was given to the design of the reference energy system (RES) common to all countries, which had to be sufficiently disaggregated to provide the required contributions to the set objectives but not so disaggregated that the required data would not be available, and that the resulting size of the linear programming problem would be difficult to handle by the optimiser and other software. Once the RES was agreed upon, the next step dealt with the design of spreadsheets and databases used to manage the data-input in a transparent and comprehensive way, as discussed below. 


\subsection{The reference energy system}

From a methodological point of view, the first decision taken refers to the definition of the RES. As extensively described in the official deliverable [10], the following sectors were included: residential, commercial, agriculture, industry, transportation, electricity/heat production, and energy supply. In particular, the structure of the RES was determined by identifying the demand categories, energy carriers, emissions, and materials to include.

In brief:

- Transportation includes road and rail for passengers and freight, navigation and aviation. In road transport, there are five demand categories for passenger travel (cars - short distance, cars - long distance, buses - urban, buses - intercity, two and three-wheelers/off road) and trucking. In rail transport, there are three demand categories (passengers - light trains (metros), passengers - heavy trains, and rail freight). The aviation and navigation sectors are modelled using a single generic technology each and a single generic demand each that reproduces the energy consumption.

- In residential there are 11 end-uses (space heating, space cooling, water heating cooking, lighting, refrigeration, cloth washing, cloth drying, dish washing, other electric, other energy), and the first three are differentiated by building categories (single house - rural, single house urban, multi-apartment). Similarly, the RES structure of the commercial sector has nine end-uses (space heating, space cooling, water heating, cooking, refrigeration, lighting, public lighting, other electric, other energy uses), with the first three being differentiated by building categories (small/large). Agriculture is modelled as a single generic technology with a mix of fuels as input and an aggregated useful energy demand as output.

- Industry is divided into two different sets: energy intensive industries and other industries. For the energy intensive industries, a process-oriented RES was adopted, whereas for other industries a standard structure consisting in a mix of five main energy uses (steam, process heat, machine drive, electrochemical, others processes) was adopted. To start moving in the direction of LCA/I and ExternE, different material demands of the industrial sector (e.g. steel or limestone) were modelled separately.

- Electricity and heat production: this sector regroups public power plants, auto production of electricity and combined heat and power. In the RES, three types of electricity (high voltage, medium voltage, and low voltage) and two separated (not connected) grids for long distance (high temperature) and short distance (low temperature) heat are distinguished.

- Supply: Each primary resource (crude oil, natural gas, hard coal, lignite) is modelled by a supply curve with several cost steps. There are three categories of sources: located reserves (or producing pools), reserves growth (or enhanced recovery), and new discovery. In addition, five types of biomass are modelled: wood products, biogas, municipal waste, industrial waste-sludge, and bio fuels.

Energy carriers were chosen starting from those reported in the Eurostat [11] energy balances, and then aggregating some of them to adapt the list to the modelling objectives of the project. As concerns materials, it was decided to explicitly model only those whose production requires more energy or which are important for the production processes modelled (e.g. scrap steel). Other materials are implicitly modelled as part of the variable costs and their related emissions are accounted for in the process emissions. The air emissions modelled are carbon dioxide $\left(\mathrm{CO}_{2}\right)$, carbon monoxide $(\mathrm{CO})$, methane $\left(\mathrm{CH}_{4}\right)$, sulphur dioxide $\left(\mathrm{SO}_{2}\right)$, nitrogen oxides $\left(\mathrm{NO}_{x}\right)$, 


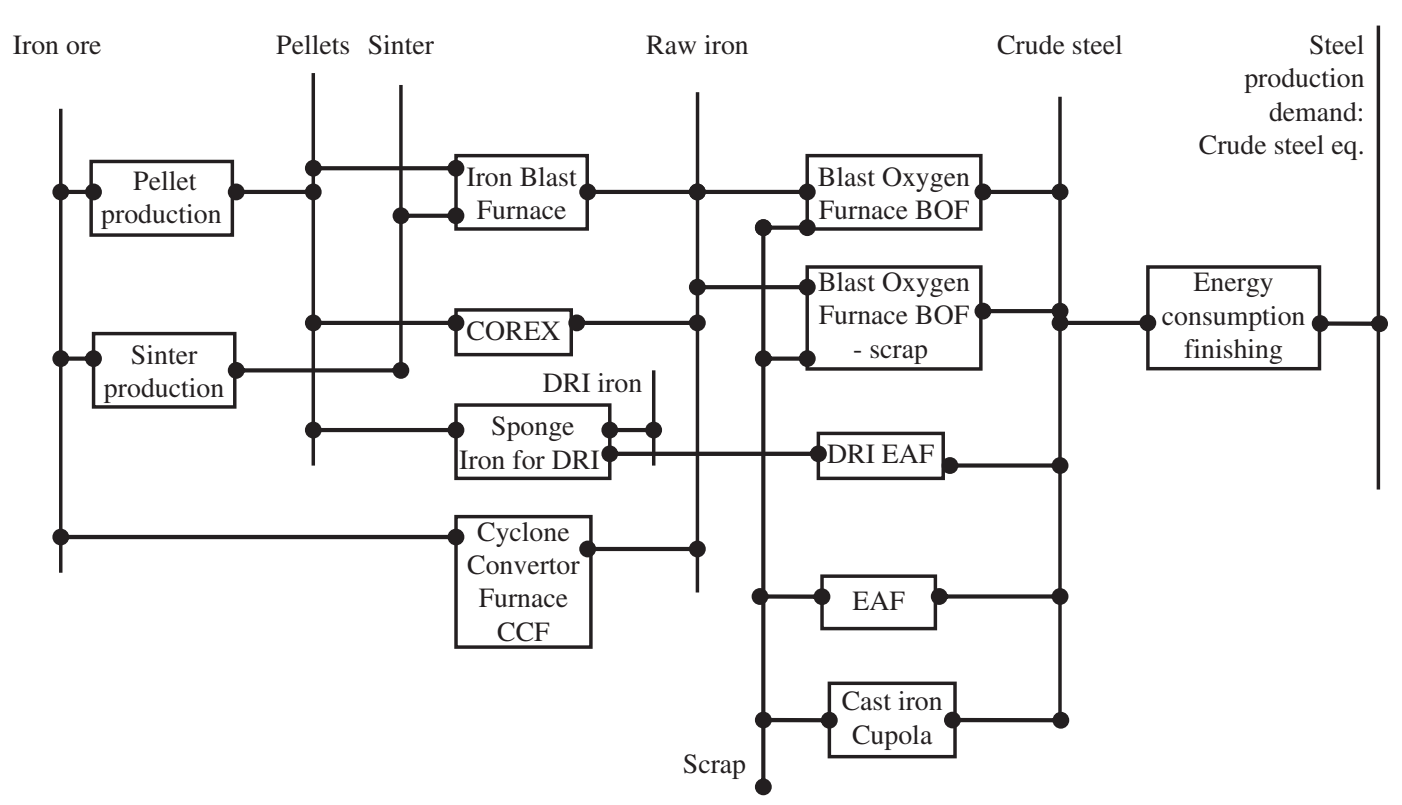

Figure 1: A RES example: the iron and steel industry (Source: ECN).

nitrous oxide (NO), particulate (PM 2.5 and PM 10), volatile organic compounds (VOC), sulphur hexafluoride $\left(\mathrm{SF}_{6}\right)$ and fluorocarbons $\left(\mathrm{C}_{x} \mathrm{~F}_{y}\right)$.

A RES example for the iron and steel industry, with the indication of the materials considered is shown in Fig. 1.

\subsection{Integration of LCA and External Costs}

The key and sufficient condition to integration is the harmonisation of the data flows (exogenous and endogenous to the project) that are common to the various streams. Figure 2 sketches the main blocks of the entire project and identifies the data links between them.

Integration occurs at different levels. First, a large number of bilateral exchanges of data (concerning individual technologies and/or individual emissions) take place between research streams. This data harmonisation will, among other things, result in the constitution of a common technology database for the electricity generation sector, to be used as one input to the TIMES modelling work of stream 2a. This database includes all techno-economic data as well as data concerning LCA and externalities for the technologies concerned. Second, a multi-lateral integration of data takes place, as follows: Stream $2 \mathrm{a}$ is responsible for providing the list and complete description of a number of scenarios (baseline and policy scenarios). Using the common technology database and the scenario information, RS2a will then proceed to simulate the technology and fuel pathways corresponding to each scenario, using the TIMES Pan-EU model. There will be one pathway per scenario simulated. The results of these simulations will be made available to all streams.

2.2.1 Harmonisation of exogenous data

The top box in Fig. 2 represents a large amount of data and assumptions that are pure inputs to all or some models (they are called exogenous for that reason). These data are of two types: (a) technical 


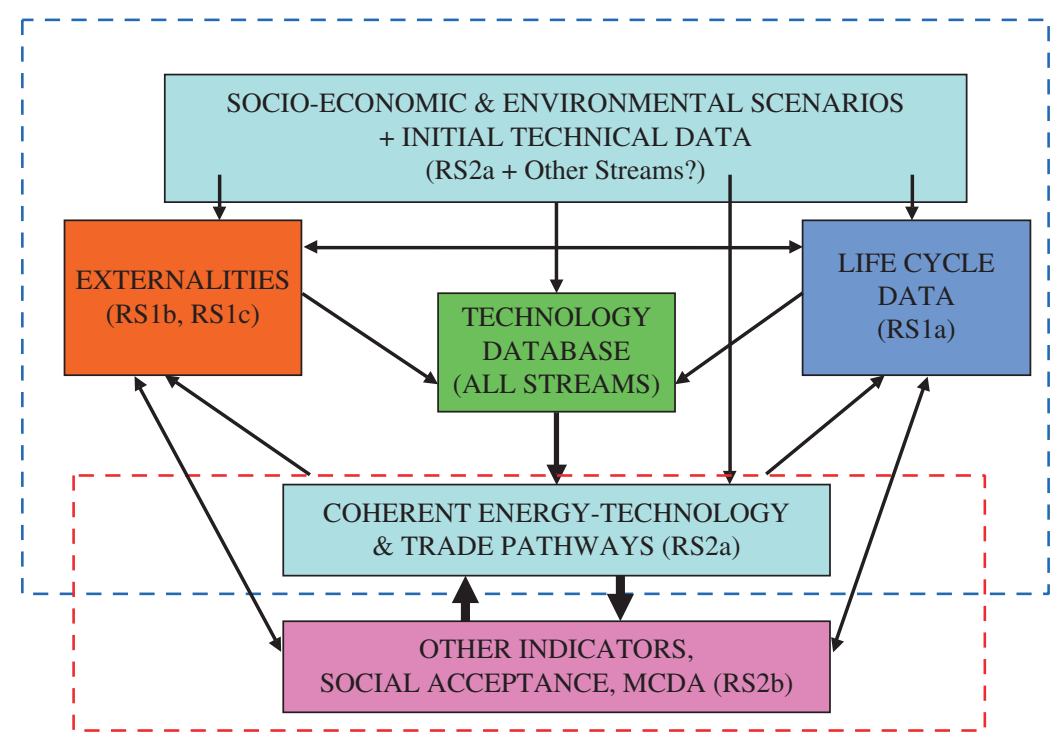

Figure 2: Integration between research streams [12].

economic data on the list of common technologies and (b) scenario assumptions. These data will be provided by RS2a and made available to all streams. We give a few details on these data in Section 2.4. The initial technological data provided by RS2a should not hide the fact that the other streams will be collecting a host of very detailed and focused data on technologies. Whereas the data to be provided by RS2a is the minimum core data on which harmonisation is required across all streams, there will also be data collected, created, and used by streams $1 \mathrm{a}, 1 \mathrm{~b}, 1 \mathrm{c}$, and $2 \mathrm{~b}$ that will constitute large, detailed databases.

\subsubsection{Technology data}

Since the TIMES model is an integrated techno-economic energy model, its database includes technologies in all sectors of the economy, namely primary energy extraction, energy processing and conversion, energy transport, and end-uses by four main sectors (residential, commercial, industry, transportation). Thus, the TIMES database will be concerned with more than a thousand technologies in each country model. In addition, the Pan-European model represents the main energy exchanges between EU and with non-EU countries, where each energy trade is modelled via a trade technology (pipeline, trucking, shipping, transmission grid). Among these, an important subset of technologies has been targeted for detailed LCA analysis. They concern the vast majority of the electric power generation sector, which is the focus of stream RS1a, and the technologies used for the transport of imported oil and gas, which are the focus of stream RS1c. These will constitute the set of common technologies. In what follows, we use the TIMES view of technology data, since it represents the minimum required data that will serve as vehicle for the integration across all streams.

Regarding the types of scenario envisioned, the general idea is to build first a Baseline scenario where all drivers are specified. This scenario should be in line with the assumptions used in similar projects of the EU commission. For the other (alternate) scenarios we will limit ourselves to a 
partial equilibrium framework in the sense that the macroeconomic assumptions remain those of the reference scenario.

\subsubsection{Life cycle data}

The TIMES model possesses the required features to represent the consumption (or release) of energy and materials during the entire life cycle of each technology and fuel, as well as the atmospheric emissions produced at each stage. The life cycle of a technology may be decomposed into three phases: construction, operation and dismantling. At each phase, some energy forms and materials are usually consumed and/or released, and the production/disposal of these materials and energy forms itself requires additional materials and energy. This may be sketchily represented as in the upper part of Fig. 3. For example, consider a coal power plant. Its construction consumes cement, bricks, steel, etc., and also some fuels to operate the construction machinery. The production of each of these construction inputs itself consumes additional fuels and materials as well (represented by the top boxes in Fig. 3), and releases emissions and perhaps other substances (represented by the bottom boxes). Similar inputs apply to the operation and the dismantling of the plant.

A similar, although slightly simplified, representation of a technology's life cycle is obtained if the energy and materials produced or released at construction (or dismantling) time are replaced by the total integrated emissions resulting from the production and use of these materials/energy forms. This is sketched in the lower part of Fig. 3. This latter approach is preferred to the first one, as it represents a streamlined set of data exchanges between LCA and TIMES. In the preferred approach, the data requested of RS1a consist of the amounts of 'emissions' due to construction, whether they occur at construction time or upstream for the production and transport of the energy and materials used for construction.

\subsubsection{External costs}

External costs are briefly defined as those effects on individuals or the society, quantified in monetary terms, and not taken into account by the originator. An important contribution to external costs is caused by the release of substances from the energy systems. In the case of TIMES, the substances considered are those emitted into the atmosphere.

There are several complex intermediate steps between the emission of a pollutant and the damages caused by it. These steps are studied in much detail by stream RS1b and constitute a large part of the work of streams RS1b and RS1c. These steps are not explicitly and separately modelled in TIMES. Instead, TIMES has a representation of the damage cost induced by one unit of each substance emitted in each country, in the form of a damage cost coefficient (e.g. the damage cost due to one tonne of $\mathrm{SO}_{2}$ emitted in France). An ex-post computation of country specific damage costs can be done using coefficients provided by RS1b.

Furthermore, the damage factors for the local and regional pollutants will be derived specifically by source sectors like residential/commercial, industry (where necessary subdivided into iron/steel production etc.), energy (power plants, refineries, gas distribution etc.) and transport (subdivided into urban/non-urban). This specification is needed to tackle the variation in the damage costs caused by different source characteristics.

For external costs occurring outside Europe (e.g. due to resource extraction) and external costs not related to airborne pollutants (e.g. noise), damage factors per activity of a technology (e.g. per kW h, per vehicle-kilometre) will be provided.

This approach implicitly assumes that the cost is proportional to emissions, a statement that may be inaccurate if the range of variation of emissions is very large. However, for reasonably narrow ranges of emissions, it is expected that the proportionality assumption will hold. 

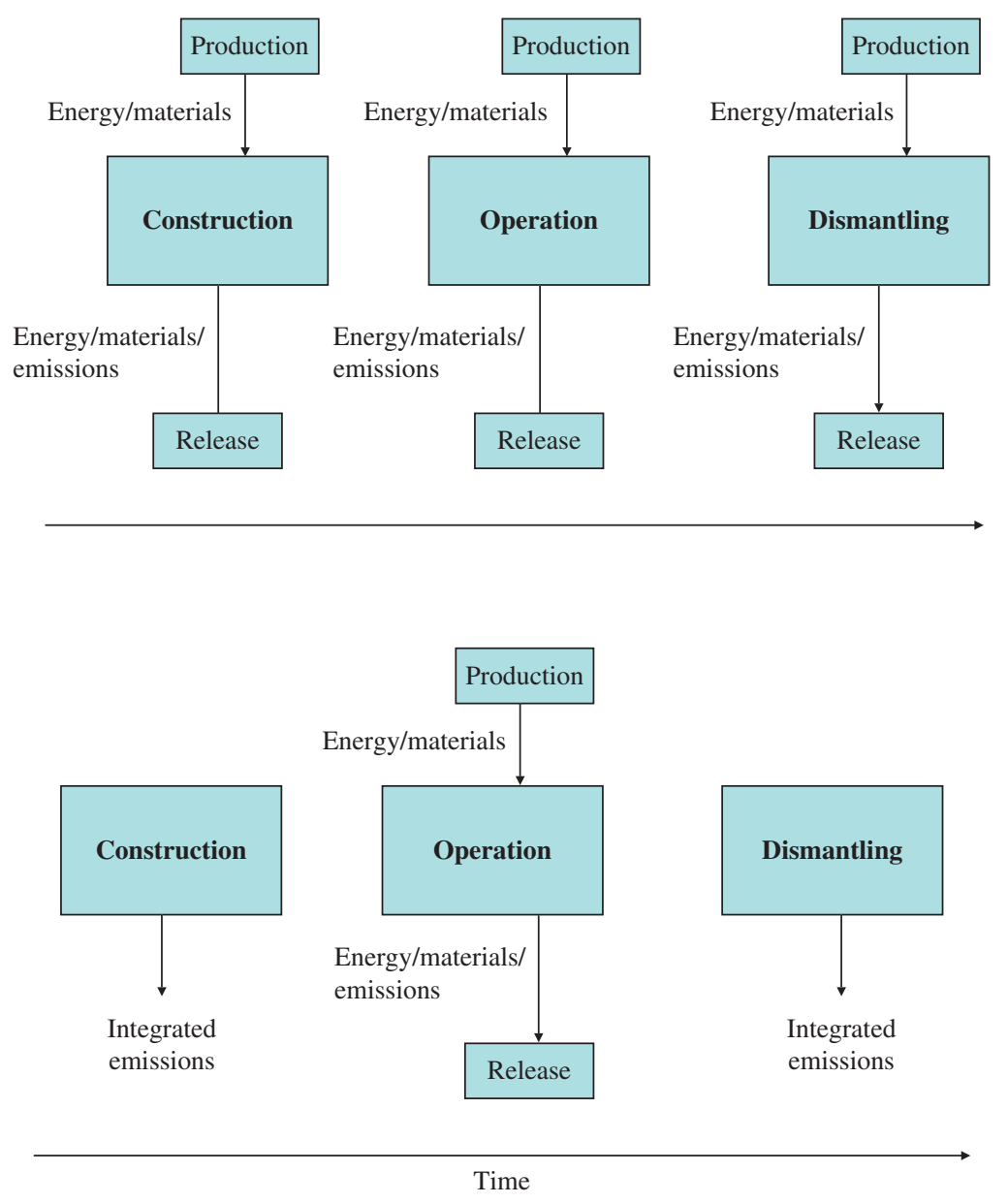

Figure 3: The life cycle of a typical technology. The lower part of the figure represents the compromise adopted in the project.

Once the external cost coefficients have been injected into TIMES and the model is run, a new solution (including the emission levels) becomes available to all streams for further analyses.

\subsection{The base-year calibration}

The first step of the energy system analysis at country level dealt with the calibration of the model to selected data sources in the initial year. The Eurostat database was chosen as the main official common source of information. The section 'Energy and Environment' provides all the energy flows (production, transformation, consumption, trade) for the base-year (2000), as well as the net installed capacities for power plants, several technological parameters for nuclear plants (efficiency, availability, etc.) and import/export figures. As concerns transportation modes, the Eurostat data were integrated with those provided by DG TREN [13], whereas default inputs and outputs of energy 


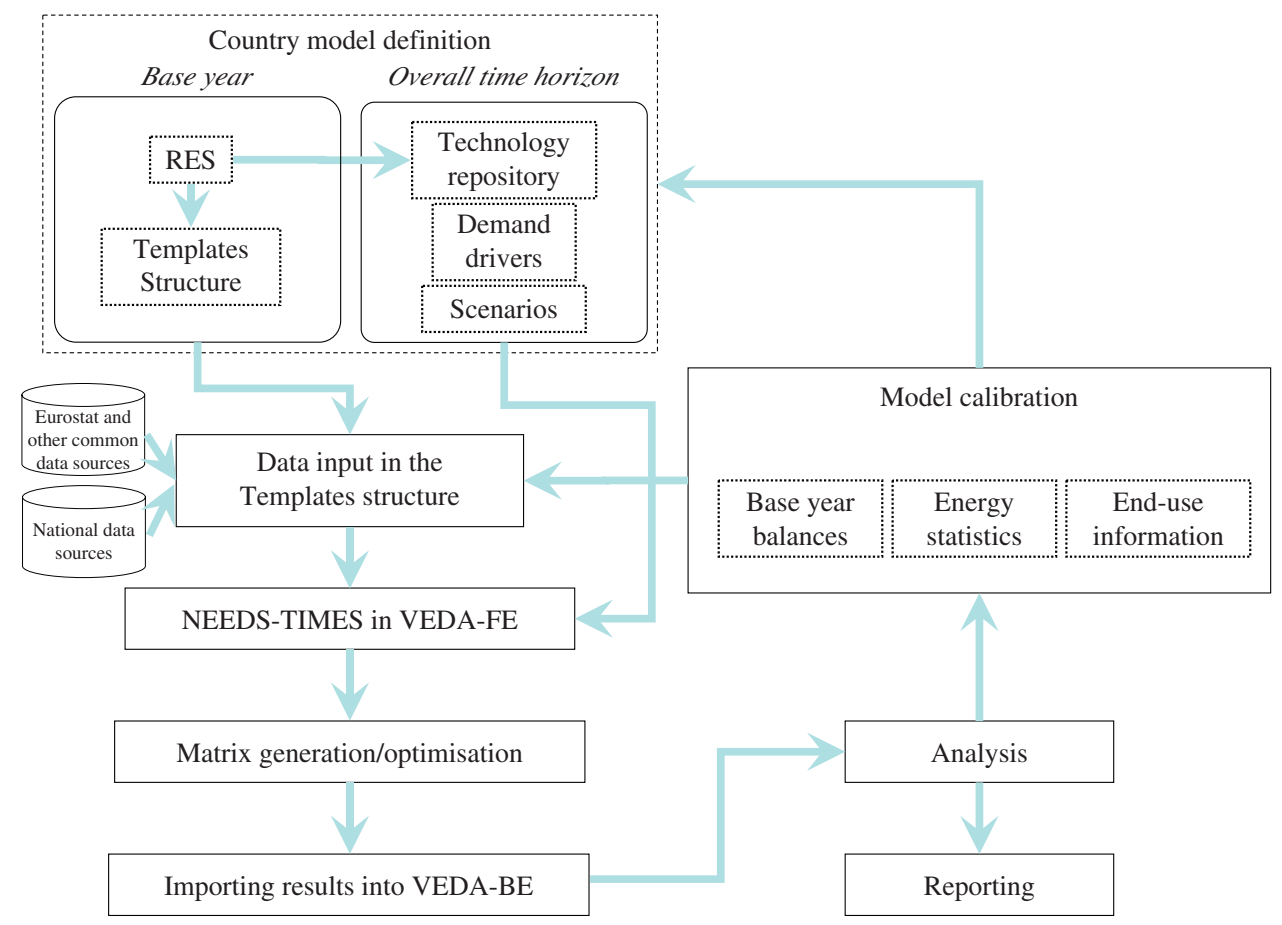

Figure 4: Schematic representation of the modelling process.

intensive technologies (European average) come from the Western European Matter database of ECN [14]. In some cases, such as Italy, it has been necessary to correct major errors in the initial energy balances using national data sources.

The characterisation of the analysed sectors was done by filling in five 'templates' (RCA: residential/ commercial/agriculture, IND: industry, TRA: transport, ELC: electricity/heat production, and SUP: energy supply), which are elaborate Excel spreadsheets that lay down the basic structure of the country TIMES model and hold the data necessary to calibrate the energy flows of the base-year. Templates have direct links to primary data sources and are periodically updated. The templates collect the following information: base-year energy flows, existing technology stocks, with their technical/environmental characteristics, discount rate, and transmission efficiency. With these data consistent base year demands for energy services are computed.

As sketched in Fig. 4, once the energy system has been characterised for the base year using the templates structure, these files are imported into VEDA-FE for running the TIMES model. The integration scheme for the whole process from data to model is given in Fig. 4.

Once the results of the base year are 'stable', the investigation can be extended to the overall time horizon, as discussed in the following section.

\subsection{The long-term analysis}

An analysis over a 50-year time horizon requires three additional inputs into VEDA-FE:

- Specification for existing and future technologies and fuels. 
Table 1: Typical structure of a technology definition.

\begin{tabular}{|c|c|c|c|c|c|}
\hline Technology name Parameter & Unit & Constant & 2000 & {$[\ldots]$} & 2050 \\
\hline Capacity & $\mathrm{kW}$ & $\ldots$ & & & \\
\hline Activity & GW h & & & & \\
\hline $\begin{array}{l}\text { Units of annual production activity } \\
\text { per unit of capacity (CAPUNIT) }\end{array}$ & GW h/GW & $\ldots$ & & & \\
\hline Life & Year & $\ldots$ & & & \\
\hline $\begin{array}{l}\text { The first time period of availability } \\
\text { of the technology (START) }\end{array}$ & Year & $\cdots$ & & & \\
\hline Output(s) & $\begin{array}{l}\text { Share (range } 0-1 \text { ) or } \\
\text { GJ/ton material }\end{array}$ & $\ldots$ & & & \\
\hline Input(s) & $\begin{array}{l}\text { Share (range } 0-1 \text { ) or } \\
\text { GJ/ton material }\end{array}$ & $\ldots$ & & & \\
\hline $\begin{array}{l}\text { Availability (should account for } \\
\text { both forced and scheduled outages } \\
\text { during the entire year) }\end{array}$ & Average per year $(\%)$ & & $\ldots$ & $\ldots$ & $\ldots$ \\
\hline Efficiency & $\%$ & $\ldots$ & $\ldots$ & $\ldots$ & $\ldots$ \\
\hline Investment cost (INVCOST) & M€2000/GWth & & $\ldots$ & $\ldots$ & $\ldots$ \\
\hline $\begin{array}{l}\text { Annual fixed operating and } \\
\text { maintenance cost associated with } \\
\text { the installed capacity (FIXOM) }\end{array}$ & M€2000/GWth & & $\ldots$ & $\ldots$ & $\ldots$ \\
\hline $\begin{array}{l}\text { Annual variable operating and } \\
\text { maintenance cost (VAROM) }\end{array}$ & M€2000/GWhe & & $\ldots$ & $\ldots$ & $\ldots$ \\
\hline Emissions & kton (or ton)/PJ input & $\mathrm{CO}_{2} / \mathrm{CO} / \ldots$ & $\ldots$ & $\ldots$ & $\ldots$ \\
\hline $\begin{array}{l}\text { Decimal fraction of device output } \\
\text { meeting demand, when a device } \\
\text { contributes to several demands } \\
\text { (OUTDM) }\end{array}$ & Share & Demand & $\cdots$ & $\cdots$ & $\cdots$ \\
\hline
\end{tabular}

GWth: GW thermal; GWhe: GWh electric.

- Demand drivers and elasticities.

- Scenario parameters.

Technical and economic information on each existing and future technology in each sector (residential, commercial, industry, transportation, supply and power generation) over the entire time horizon is provided in Excel files. This information can also include data on life cycle emissions and external costs.

An example of the basic structure of the main data characterising a technology is shown in Table 1.

Table 2 is an illustrative example of the typical input data for a set of power plants and is compiled based on a set of references described by Blesl et al. [15].

- European Pressurised Water Reactor (EPR) with a net capacity of 1590 MWe and a net thermal efficiency of 37\%. The fuel enrichment of about $4.9 \%$ and the average burn-up of $65 \mathrm{MWd} / \mathrm{kg}$ are taken into account. 
Table 2: Technical and economic data of nuclear and fossil power plants for the year 2010.

\begin{tabular}{|c|c|c|c|c|c|c|c|}
\hline & Unit & EPR & $\begin{array}{l}\text { PFC } \\
\text { (hard } \\
\text { coal) }\end{array}$ & $\begin{array}{c}\text { IGCC } \\
\text { hard coal }\end{array}$ & $\begin{array}{c}\text { IGCC } \\
\text { with } \mathrm{CO}_{2} \\
\text { capture }\end{array}$ & $\begin{array}{c}\mathrm{PFC} \\
\text { (lignite) }\end{array}$ & CCGT \\
\hline Electrical capacity & MWe & 1590 & 800 & 450 & 425 & 1050 & 1000 \\
\hline Net thermal efficiency & $\%$ & 37 & 46 & 51 & 45 & 45 & 60 \\
\hline $\begin{array}{l}\text { Specific capital investment } \\
\text { costs }\end{array}$ & $€ / \mathrm{kW}$ & 1550 & 820 & 1200 & 1500 & 1150 & 440 \\
\hline $\begin{array}{l}\text { Specific decommissioning } \\
\text { costs }\end{array}$ & $€ / \mathrm{kW}$ & 155 & 34.5 & 53.3 & 58.5 & 32.4 & 15.8 \\
\hline Specific fixed O\&M costs & $€ / \mathrm{kW} /$ year & 30.0 & 36.6 & 56.4 & 68.9 & 35.5 & 18.8 \\
\hline $\begin{array}{l}\text { Specific variable operating } \\
\text { costs without fuel costs }\end{array}$ & $€ / M W ~ h$ & 3.6 & 2.7 & 3.2 & 3.8 & 1.0 & 1.6 \\
\hline
\end{tabular}

- Coal-fired pulverised-fuel steam plant (PFC (hard coal)) with overcritical conditions (285 bar $/ 600^{\circ} \mathrm{C}$ ) of steam. The net capacity is $800 \mathrm{MWe}$ and the net thermal efficiency is about $46 \%$.

- Coal-fired integrated gasification combined cycle (IGCC hard coal) has a net capacity of $450 \mathrm{MWe}$ and a net thermal efficiency of $51 \%$.

- Coal-fired integrated gasification combined cycle with equipment for $\mathrm{CO}_{2}$ capture (IGCC with $\mathrm{CO}_{2}$ capture). This plant has a net capacity of $425 \mathrm{MWe}$ and a net thermal efficiency of $45 \%$.

- Lignite-fired pulverised-fuel (PFC-lignite) steam plant, with a new sophisticated technology for drying lignite $(\mathrm{BoA}+)$ and overcritical steam conditions. The net electrical capacity is 1050 MWe with a net thermal efficiency of $45 \%$.

All cost estimates for steam cycle plants are based on plant types that are already built or approved. For nuclear plants, costs incurred during the time between plant shutdown and plant decommissioning is also taken into account included in the specific capital investment costs.

All fossil fuel-fired power plants are designed to fulfil environmental protection standards. For coal-fired power plant with $\mathrm{CO}_{2}$ capture (IGCC with $\mathrm{CO}_{2}$ capture), an $88 \%$ removal rate is taken into account. The total power generating costs consist of the overnight capital costs, operation and maintenance $(\mathrm{O} \& \mathrm{M})$ costs and fuel costs. Costs for refurbishment are considered as 'fixed operating costs' and are covered by the O\&M costs. For fluctuating sources of electricity generation, such as hydro, wind and solar, additional costs have to be included considering adequate standby generation. Electricity generation costs are calculated with an interest rate of 5\%. It is assumed that the depreciation time is equal to the technical lifetime of a plant and that the average load factor of all power stations shown in Table 2 is $85 \%$.

The demand drivers allow generating the demand projections of energy services over the time horizon for the reference scenario (business as usual - BAU) as well as for the policy scenarios. In operational terms, the scenarios consist of sets of coherent assumptions about the future trajectories of demand drivers (population, GDP, sectors' outputs, households, etc.), leading to a coherent organisation of the system under study [7]. For a TIMES model, once the drivers are determined and quantified, a set of energy service demands over the horizon is determined by specifying the elasticity of each demand to its respective driver, in each region, using the following general formula:

Demand's growth rate $=$ Driver's growth rate $\times$ Elasticity. 
In the NEEDS - TIMES model, for the reference scenario BAU [16], that follows business as usual trends, the general equilibrium model GEM-E3 Europe is used to produce the drivers' growth rates (GDP, sectors' growth, households, transport demand by households) in the various regions, based on assumptions on population growth, technical progress, and taking into account the recent developments in the oil and gas markets and the new DGTREN projection. It includes also the implementation of the Kyoto climate policy (with constant and moderate tax levels after 2012), and the adopted country decisions on nuclear energy [16].

Besides that, three policy scenarios of interest for EU stakeholders will be analysed at the Pan-EU level [17], based on the following key issues:

- Long-term post-Kyoto climate policy target (e.g. $550 \mathrm{ppm}$ or some other $\mathrm{CO}_{2}$-equivalent concentration).

- Enhancement of endogenous energy resources such as renewables and biofuels, and of energy conservation options through a combination of policies (renewables standards, energy efficiency standards, R\&D policy).

- Reduction in European imports for selected fuels below pre-specified levels.

- Local pollution policy targets for air quality, taking into account externalities (for which updated data will be provided by the other research streams).

Moreover, some scenarios variants will be considered regarding: the internalisation of external cost in the first two scenarios, nuclear availability or not and a more optimistic technological development (induced by appropriate EU policies) necessary to address the challenge of the $450 \mathrm{ppmv}$ stabilisation scenario [17]. A more detailed description of the model formulation to represent these policies is discussed in the Appendix.

\section{CONCLUSIONS AND FURTHER DEVELOPMENTS}

In the context of the Sixth Framework Programme's Integrated Project NEEDS, the TIMES model coded in GAMS and the VEDA interfaces will allow research teams to implement and make available a unique modelling platform, accessible to other research partners. It will be characterised by a long-term time horizon, high technological detail (in energy supply and end-use sectors), open and updateable format without need to change the software. Moreover its built-in flexibility facilitates the integration of LCA and ExternE evaluation methodologies.

The first steps of the work were directed to software development and implementation and to the development of the 29 country models that will constitute the basis of the Pan-European model. Next steps will deal with the finalisation of the Pan-European model, testing its consistency in the reference scenario as well as on policy scenarios.

The main model output of scenario analysis, for a given policy option and the set of exogenous assumptions adopted, is the energy system response for the time horizon under analysis. Illustrative parameters of this response are the equilibrium quantities and prices of energy vectors (primary energy and secondary fuels), the shadow prices for each policy constraint, energy technologies, emissions (greenhouse gases and local air pollutants) and other burdens are provided. These results will constitute new input data for both LCA and ExternE, to be used for iterative, convergent evaluations.

This work will provide the foundation for including the end-use technologies in the LCA and ExternE approach for balancing the environmental impacts for the whole energy system. Another important set of analysis will deal with the assessment of the market allocation of new technologies and with the analysis of different policies and measures to support national policies, providing a common framework for the definition of EU strategies. 
Finally, important is to conclude that the Pan-European TIMES model is more than the sum of the 29 national models as it can demonstrate the benefits of coordinated policies across the borders of Europe contrasting them with the fragmentation of national policies.

\section{ACKNOWLEDGMENTS}

This work was performed in the framework of the EU NEEDS project (Contract number 502687), coordinated by the Institute of Studies for the Integration of Systems - ISIS, Rome (Italy) and supported by the Directorate General for Research of the European Commission in the context of the VI Framework Programme, Priority 6.1: Sustainable Energy Systems, Sub-priority 6.1.3.2.5: Socio-economic tools and concepts for energy strategy.

\section{APPENDIX: POLICY FORMULATION IN TIMES}

\section{A.1 Reduce import dependency}

Different policy targets can be formulated where either the EU imports (or imports by country) for fossil fuels (e.g. oil, gas, coal) are reduced below some pre-specified levels, with EUIfr $r_{f f, t}$ being the fractional import reduction for fuel $f f$ relative to the estimated imports in the BAU case, which is described by the known parameter $\sum_{r, f f} B A U_{-} I M_{r, f f, t}$. This EU-wise constraint defines equal marginal costs of imports for fuel $f f$ across borders.

$$
\sum_{r, f f} I M_{r, f f, t} \leq\left(1-E U I f r_{f f, t}\right) \cdot \sum_{r} B A U_{-} I M_{r, f f, t}
$$

The consequence of this constraint is the increased diffusion of conservation and efficiency improvements measures as well as renewables and nuclear to substitute for fossil imports. This assessment of reduced import dependency could also help identifying policy standards related to the penetration of renewables, efficiency standards, biofuels, etc.

\section{A.2 Renewable standards}

The relative share of renewable in either the production of electricity or in primary energy use could be forced above a given value regarded as a renewable policy standard.

$$
\sum_{r, r e n} E L E_{r, r e n, t} \geq F R_{E U, t} \cdot \sum_{j \in \text { powerplants }} E L E_{r, j, t}
$$

with $F R_{E U}$ defining the relevant Pan-European policy standard and $E L E_{r, \text { ren, }}$ being the model variables defining the production of renewable electricity plant $r e n$, in region $r$, and time $t$. One could also impose penetration rates on the national level but the above formulation will define equal marginal cost per unit of renewable electricity across European boundaries and can be interpreted as equivalent solution to a green-certificate trade policy with zero transaction costs.

\section{A.3 Carbon emissions stabilisation policies}

A few options are possible here.

In the first case a stabilisation target for $\mathrm{EU}$ is proposed that sets the optimisation approach free to allocate regional reductions by country, with $f r_{E U, t}$ being the Pan-European reduction target relative 
to the emissions in 1990. This fraction could be between $50 \%$ and $60 \%$ of the emissions in 1990, for the year 2050, in the case that a $450 \mathrm{ppmv}$ global $\mathrm{CO}_{2}$ concentration is proposed.

$$
\sum_{r, f f} P E_{r, f f, t} \cdot S E_{f f} \leq\left(1-f r_{E U, t}\right) \cdot E_{E U, 1990}
$$

And, a second case, where a priori regional reduction targets $f r_{r, t}$ are imposed

$$
\sum_{r, f f} P E_{r, f f, t} \cdot S E_{f f} \leq \sum_{r, f f}\left(1-f r_{r, t}\right) \cdot B A U_{-} P E_{r, f f, t} \cdot s e_{f f}
$$

with $f r_{r, t}$ defining the fractional reduction of carbon emissions below the BAU case by region and time such that the stabilisation target is fulfilled. This fraction takes into consideration the aspiration of EU countries for economic development and their ability to contribute to climate policy and results to the same overall reduction as the first option. (The formulations above apply a $\mathrm{CO}_{2}$ balance on the primary energy use of fossil fuels based on their specific emission coefficients where sequestration options for electricity generation associated with negative emission coefficients per unit of $\mathrm{kW} h$ produced are explicitly taken into account. Similar relations can be written when emissions are balanced as commodities associated with explicit technologies.) Finally, another possibility would be to impose a tax across Europe such that cumulative emissions trajectories consistent with the desired concentration target for the time horizon of analysis are defined.

\section{A.4 Externalities}

Externalities compensate for induced damages of pollution by imposing an external tax per pollutant such that the marginal control costs equal the marginal benefits of avoided emissions. For example, the production cost per unit of electricity could be expressed as a function of the annualised capital $\operatorname{cost}\left(S C I_{j, t} \cdot a c f_{j}\right)$, the fixed (fixom) and variable (varom) O\&M cost and the fuel cost. If the emissions generated per unit of $\mathrm{kW} \mathrm{h}\left(s e_{p o l}\right)$ contribute to an externality, this can be compensated by applying the corresponding tax $\left(E X T a x_{p o l}\right)$ for the induced damages. The inclusion of the tax will reflect the full cost of power generation, as shown in the following equation and it will change the solution reducing the release of pollutants contributing to environmental damages, while the valuation of this tax will be the task of research stream RS1b.

$$
G C_{j, t}=\left(S C I_{j, t} \cdot a_{j}+\text { fixom }_{j}\right) /\left(p f_{j} \cdot 8760\right)+\text { varom }_{j}+P r_{\text {fuel }} / \eta_{j}+\text { EXTax }_{p o l} \cdot \text { se }_{p o l}
$$

A.5 Endogenous learning

$$
S C_{j t}=S C_{j 0} \cdot\left[\frac{C C_{j t}}{C C_{j 0}}\right]^{-\beta_{j}} \cdot\left[\frac{C u m_{-} N E W_{-} R \& D_{j t}}{C u m_{-} R E F_{-} R \& D_{j t}}\right]^{-\gamma_{j}}
$$

The specific cost $S C_{j t}$ of technology $j$ could be reduced due to 'learning by doing' (i.e., the term $\left[C C_{j t} / C C_{j 0}\right]^{-\beta_{j}}$ ) and due to R\&D support over the reference case based on the cumulative $\mathrm{R} \& \mathrm{D}$ budget. $\beta_{j}$ and $\gamma_{j}$ are the learning by doing and learning by searching elasticity; $C C$ is the cumulative capacity; $C u m_{-} R E F \_R \& D$ is the reference cumulative R\&D budget; and $C u m \_N E W_{-} R \& D$ is the scenario specific cumulative R\&D budget per technology $j$.

The size of the model makes it impossible to consider such endogenous treatment of learning and this is the reason that this is not specified in the list of deliverables of RS2a. But, one can 
always (1) use the above relations to adjust directly the costs due to R\&D policies and (2) take into consideration the penetration of technologies in a single region Pan-European model in the policy cases, and define ex-post for the full-scale model the corresponding cost reductions. This simple model will respect the energy balances for EU, including imports, the resource availability and it will be based on the same RES and technology repository. Finally, global growth models with endogenous technological learning applied for the same set of advanced technologies could be considered explicitly in the $450 \mathrm{ppm}$ case to define the improved performance of these technologies.

\section{REFERENCES}

[1] NEEDS, New Energy Externalities Developments for Sustainability, http://www.needsproject.org.

[2] ETSAP, The Energy Technology Systems Analysis Programme, http://www.etsap.org.

[3] Gielen, D., The Future Role of $\mathrm{CO}_{2}$ Capture and Storage - Results of the IEA-ETP Model, IEA/EET Working Paper, EET/2003/04, November 2003.

[4] OIAFEIA - Office of Integrated Analysis and Forecasting, Energy Information Administration, US Department of Energy, Washington, DC, The System for Analysis of Global Energy Markets (SAGE) Model of the US-EIA, DOE/EIA-M072 (2003)/1, August 2003, http://www.eia.doe.gov/bookshelf/docs.html.

[5] Rafaj, P., Kypreos, S. \& Barreto, L., Flexible carbon mitigation policies: analysis with a global multi-regional MARKAL model. Coupling Climate and Economic Dynamics, eds A. Haurie \& L. Viguier, Kluwer Academic Publishers: Dordrecht, The Netherlands, ISBN 1-4020-3424-5, 2005.

[6] Haurie, A., Kanudia, A., Loulou, R., Van Regemorter, D. \& Vaillancourt, K., The EFDA World Model, Final Report prepared for EFDA, ORDECSYS, HALOA/KANORS and KUL, 2004.

[7] Loulou, R., Remne, U., Kanudia, A., Lehtila, A. \& Goldstein, G., Documentation for the TIMES Model (Part I, II and III), Energy Technology Systems Analysis Programme (ETSAP), April 2005, http://www.etsap.org/tools.htm.

[8] GAMS, The General Algebraic Modeling System, www.gams.com.

[9] KanORS Consulting Inc., VEDA (VErsatile Data Analyst), http://www.kanors.com/ software.htm.

[10] Loulou, R., Kanudia, A., Vaillancourt, K., Smekens, K., Tosato, G.C., Van Regemorter, D., Blesl, M., Cosmi, C., Salvia, M. \& Schulz, T., Draft Common Structure of the National Country Models, Deliverable D1.4 of the EU Integrated Project NEEDS 'New Energy Externalities Developments for Sustainability', 31 August 2005.

[11] Eurostat, Statistical Office of the European Communities, http://epp.eurostat.cec.eu.int.

[12] Loulou, R., Dones, R., Droste-Franke, B., Friedrich, R., Frischknecht, R., Hirschberg, S., Krewitt, W., Kypreos, S. \& Van Regemorter, D., Integration of Research Streams: An Interim Report on the Harmonization of Methodologies, NEEDS Deliverable D4.1 RS Integration, 25 July 2005, http://www.needs-project.org.

[13] European Commission, Directorate General for Energy and Transport (DG TREN), Statistical Pocketbook 2005, http://europe.eu.int/comm/dgs/energy_transport/figures/pocket book/2004_en.htm.

[14] Kram, T., The MATTER Project: Integrated Energy and Materials Systems Engineering for GHG Emission Mitigation, BS: Report ECN-C-01-017, April 2001, http://www.ecn.n1/library/ reports/2001/c01017.html. 
[15] Blesl, M., Fahl, U., Kempe, St. \& Voß, A., Umfassender kostenvergleich: Wirtschaftlichkeit neuer Stromerzeugungstechniken im Hinblick auf eine nachhaltige Entwicklung. Kraftwerkstechnik, 104(13), pp. 32-37, 2005.

[16] Kypreos, S., Van Regemorter, D. \& Guel, T. Key Drivers for Energy Trends in EU; Specification of the Baseline and Policy Scenarios, NEEDS Internal Working Paper RS2a WP2.3, 12 January 2006.

[17] Kypreos, S. \& Van Regemorter, D. Scenarios to be Generated with the TIMES Model for NEEDS, NEEDS Internal Working Paper RS2a WP2.3, 27 February 2006.

This paper is an extended version of the one presented by the authors at the 1st International Conference on Environmental Economics and Investment Assessment, held on the island of Mykonos in 2006, Volume 98, WIT Transactions on Ecology and the Environment (ISBN: 1-84564-046-2/ Online ISSN: 1743-3541). Edited by K. Aravossis, C.A. Brebbia, E. Kakaras and A.G. Kungolos. 